
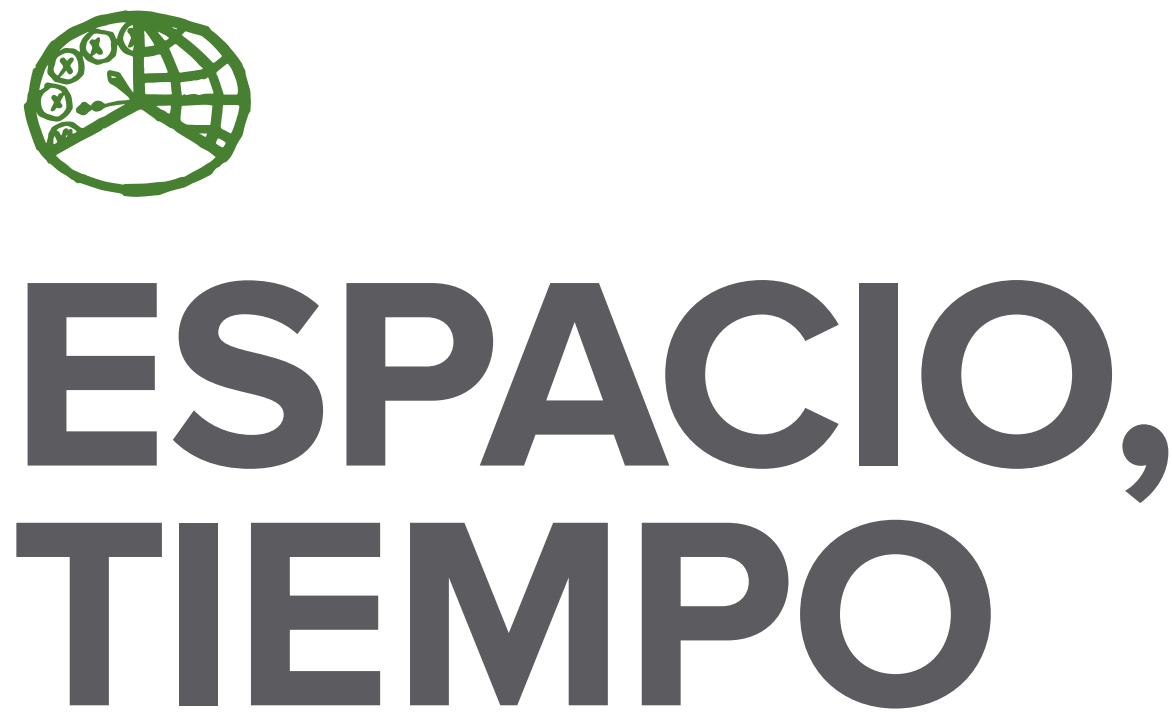

AÑOS 2013-2014

ISSN 1130-2968

E-ISSN 2340-146X
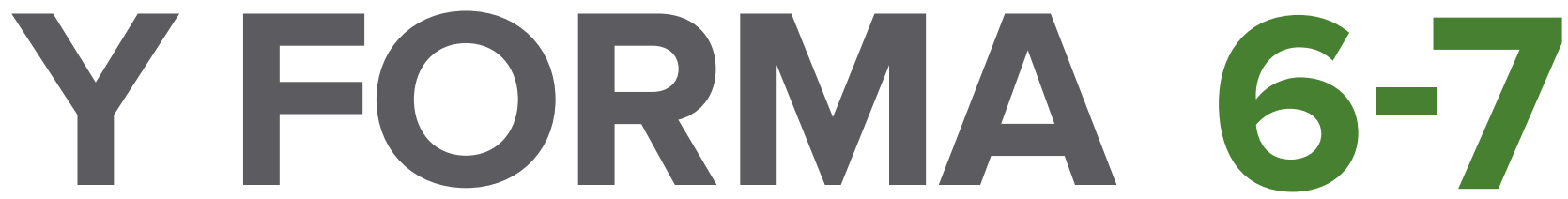

SERIE VI GEOGRAFÍA

REVISTA DE LA FACULTAD DE GEOGRAFÍA E HISTORIA 

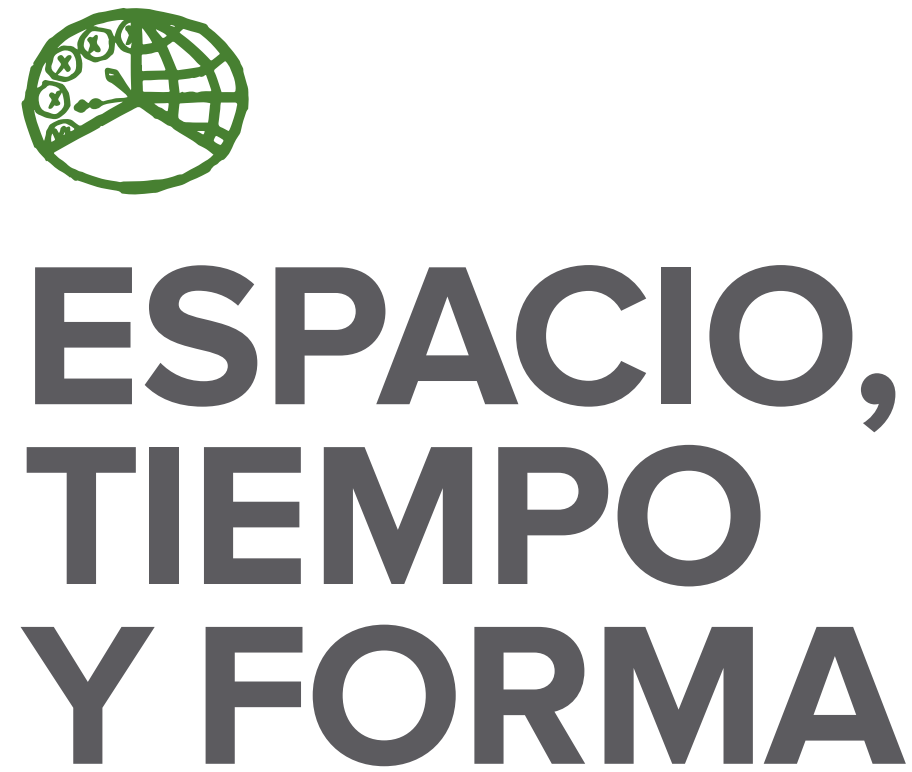

AÑOS 2013-2014

ISSN 1130-2968

E-ISSN 2340-146X

SERIE VI GEOGRAFÍA

REVISTA DE LA FACULTAD DE GEOGRAFÍA E HISTORIA

DOI: http://dx.doi.org/10.5944/etfvi.6-7.0

\section{UกED}

UNIVERSIDAD NACIONAL DE EDUCACIÓN A DISTANCIA 
La revista Espacio, Tiempo y Forma (siglas recomendadas: ETF), de la Facultad de Geografía e Historia de la UNED, que inició su publicación el año 1988, está organizada de la siguiente forma:

$$
\begin{aligned}
& \text { SERIE I - Prehistoria y Arqueología } \\
& \text { SERIE II - Historia Antigua } \\
& \text { SERIE III - Historia Medieval } \\
& \text { SERIE IV - Historia Moderna } \\
& \text { SERIE V - Historia Contemporánea } \\
& \text { SERIE VI - Geografía } \\
& \text { SERIE VII - Historia del Arte }
\end{aligned}
$$

Excepcionalmente, algunos volúmenes del año 1988 atienden a la siguiente numeración:

$$
\begin{aligned}
& \mathrm{N} .^{\circ} 1 \text { - Historia Contemporánea } \\
& \mathrm{N}^{\circ} 2 \text { - Historia del Arte } \\
& \text { N. }{ }^{\circ} 3 \text { - Geografía } \\
& \mathrm{N} .^{\circ} 4 \text { - Historia Moderna }
\end{aligned}
$$

ETF no se solidariza necesariamente con las opiniones expresadas por los autores.

Espacio, Tiempo y Forma, Serie vi está registrada e indexada, entre otros, por los siguientes Repertorios Bibliográficos y Bases de Datos: DICE, ISOC (CINDOC), RESH, IN-RECH, Dialnet, e-sPacio, UNED, CIRC, MIAR, FRANCIS, PIO, ULRICH'S, SUDOC, 2DB, ERIH (ESF).

\author{
UNIVERSIDAD NACIONAL DE EDUCACIÓN A DISTANCIA \\ Madrid, 2013-2014 \\ SERIE VI - GEOGRAFÍA N. ${ }^{\circ} 6-7,2013-2014$ \\ ISSN 1130-2968 · E-ISSN 2340-146x \\ DEPÓSITO LEGAL \\ M-21.037-1988 \\ URL \\ ETF VI · GEOGRAFÍA · http://revistas.uned.es/index.php/ETFVI \\ DISEÑO Y COMPOSICIÓN \\ Sandra Romano Martín · http://sandraromano.es \\ Ángela Gómez Perea · http://angelagomezperea.com \\ Impreso en España · Printed in Spain
}

(c) (i) (8) Esta obra está bajo una licencia Creative Commons

Reconocimiento-NoComercial 4.0 Internacional. 


\title{
PORTMÁN (LA UNIÓN, CARTAGENA): ¿CRÓNICA DE UN IMPACTO MEDIOAMBIENTAL EN VÍAS DE SOLUCIÓN? UNA BREVE REFLEXIÓN SOBRE UNO DE LOS MAYORES ATENTADOS ECOLÓGICOS EN EL LITORAL MEDITERRÁNEO
}

\author{
PORTMÁN (LA UNIÓN, CARTAGENA): \\ CHRONICLE OF AN ENVIRONMENTAL IMPACT \\ WAY OF SOLUTION? A BRIEF REFLECTION \\ ON ONE OF THE LARGEST ECOLOGICAL \\ ATTACKS ON THE MEDITERRANEAN COAST
}

Francisco José Morales Yago ${ }^{1}$

DOI: http://dx.doi.org/10.5944/etfvi.6-7.0.14859

Las imágenes presentadas son suficientemente ilustrativas, ofreciendo la realidad de cómo era y se presenta actualmente la bahía y el puerto de Portmán, al sur del municipio de La Unión (Murcia), lugar en donde no cabe dudas se han producido uno de los mayores atentados ecológicos del Mediterráneo.

La bahía de Portmán (Portus Magnus de la época romana) era hasta los años 60 del siglo pasado uno de los paisaje más bonitos del mediterráneo, históricamente había sido un lugar de salida de minerales y mercancías desde esta época pasada, siendo la huella de la actividad humana sobre el paisaje importante, pero nunca impactante. La llegada de la minería moderna desde los inicios de su explotación, en I957, de las piritas y galenas de la Sierra Minera de Cartagena-La Unión supuso la llegada de la compañía Peñarroya-España, la cual produjo enormes cantidades de escombros minerales, resultado de los métodos de extracción a cielo abierto que utilizó como forma de abaratar costes y por tanto obtener la mayor rentabilidad económica.

Al comienzo de esta nueva modalidad de extracción, los escombros eran depositados al pié de las canteras, lo que dio lugar a la formación de grandes canteras a lo que se sumó el lavado de los materiales que eran depositados en balsas, formando zonas pantanosas muy contaminadas por las partículas del mineral residual.

Tras una serie de protestas de las autoridades locales y otros colectivos frente a la empresa concesionaria que duró casi tres décadas, llegó por fin el cese de actividad de la minería y la supresión de los vertidos. Lo lamentable no fue el cierre

1. Universidad Nacional de Educación a Distancia. 

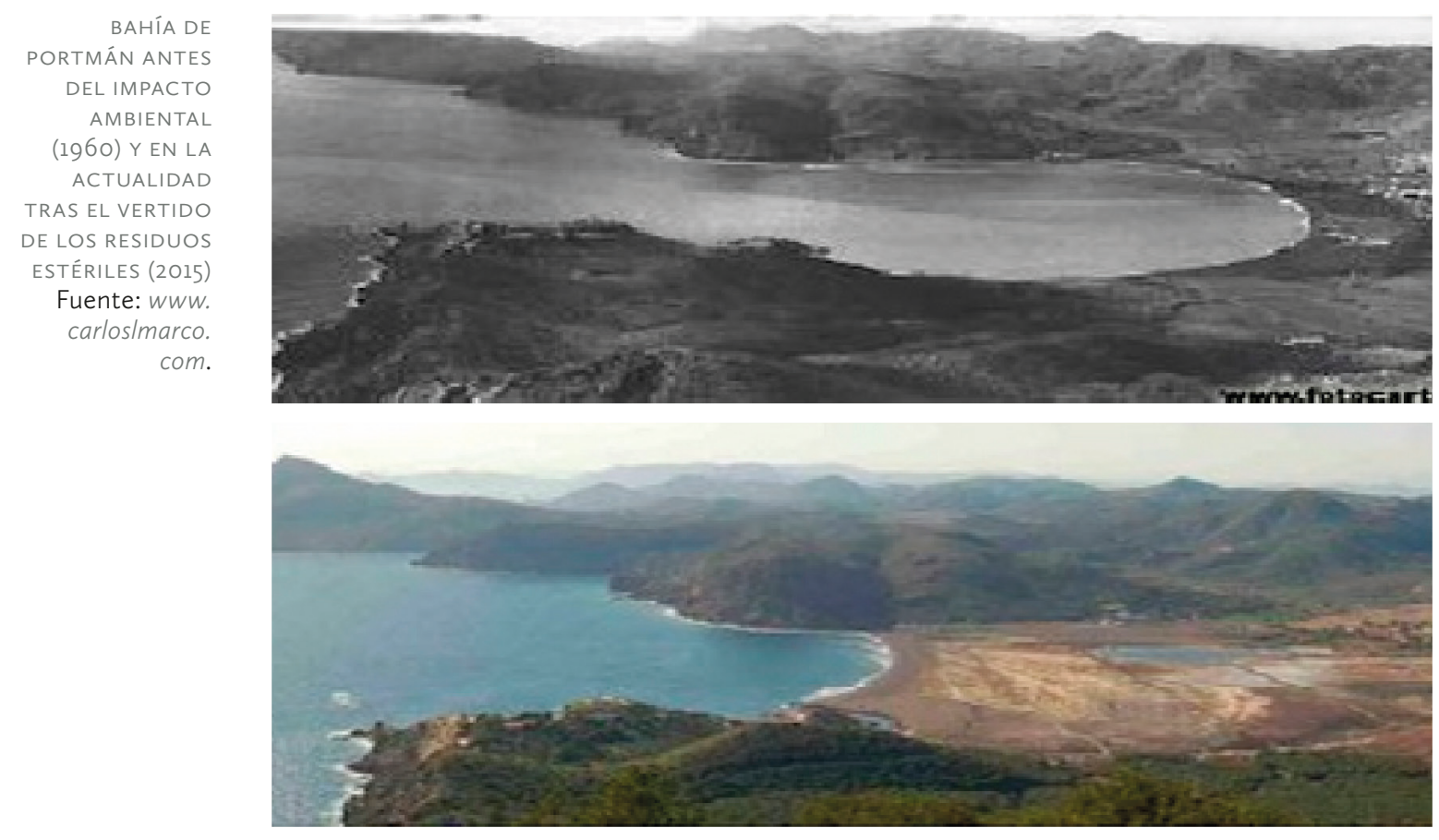

por el impacto ambiental producido, la causa principal fue que la actividad minera dejó de ser rentable para la empresa concesionaria. Se han calculado en unos 3I5 millones de toneladas de estériles minerales los depositado en esta bahía entre 1957 y 1987 , fecha de cierre de las explotaciones.

La presión popular y la concienciación de algunas autoridades políticas han hecho posible que en las últimas dos décadas se haya planteado la regeneración de la bahía, de hecho se aprobó en 201 u un proyecto, a nivel nacional y europeo, que suponía la inversión de 79.402.304 € por parte del Ministerio de Medio Ambiente.

Los cambios políticos y la llegada de la crisis a partir de 2008 , supusieron la ralentización de esta necesaria y urgente regeneración de un espacio que ofrece un importante recurso turístico y que podría ser referente para esta comarca que está necesariamente cambiando de actividad, de tal forma que los vecinos, los más directamente afectados durante más de tres décadas puedan ver de alguna manera recompensada su perseverancia y todo ello redunde en un economía sostenible y la puesta en valor de un espacio natural recuperado ambientalmente que necesariamente está unido al Proyecto de renovación del espacio minero de La Unión-Cartagena como apuesta de destino turismo industrial, con iniciativas prometedoras y realidades tan palpables, lo que ha repercutido en la puesta en funcionamiento de una visita guiada en donde se incluye una proyección o documental, el recorrido a través de un «tren minero» y la visita guiada a la mina Agrupa Vicenta, las instalaciones exteriores de la mina Pablo y Virginia así como la contemplación del lavadero «Remunerada». 


\section{Artículos · Articles}

19 María del Pilar Borderías URIBEondo

Reflexiones al finalizar la «Década de las Naciones Unidas de Educación para el Desarrollo Sostenible 2005-2014»: referencias ambientales en los Grados de la UNED y aportación de la Geografía a la EDS / Reflections at the end of the 'United Nations Decade of Education for Sustainable Development 2005-2014': environmental references in the Degree of UNED and contribution of Geography to ESD

\section{Jesús Calzadilla, José Luis López \& Aurelio VilLa}

Análisis espacial del desarrollo económico rural a nivel territorial / Spatial analysis at territorial level of rural economic development

47 David Cocero Matesanz, José Miguel Santos Preciado, María del Carmen Muguruza Cañas, fernando Santa Cecilia Mateos, maría Victoria Azcárate luxán, María del Pilar Borderías Uribeondo \& María Eugenia Prieto Flores

La utilización en los estudios urbanos de la cartografía catastral y su manejo mediante un SIG: aplicación al municipio de Getafe (Madrid) / The use in urban studies of cadastral mapping and management through GIS: application to the town of Getafe (Madrid)

73 Juan Antonio Fernández-Cañadas López-Peláez, María Palomo Segovia \& LUis Pantoja Trigueros

Delimitación espacial de las zonas probables de salida de aludes en el macizo de Peñalara mediante el uso de SIG / Spatial delimitation of the possible output zones of avalanches in the Peñalara massif using GIS techniques

Jesús Miguel García Rodríguez

Importancia patrimonial y territorial del legado hidroeléctrico en el curso bajo del Río Saja (Cantabria) / Patrimonial and territorial importance of hydroelectric legacy in the lower reaches of Saja (Cantabria)

\section{Beatriz Martínez de Teresa}

Paisaje urbano y problemática medioambiental: el caso del distrito de Retiro (Madrid) / Cityscape and environmental issues: the case of Retiro district (Madrid)

antonio Martínez Puche, Salvador Martínez Puche, joaquín Palací Soler \& Vicente Zapata Hernández

Estrategias territoriales participativas como instrumentos de diagnóstico y prospectiva, en el contexto europeo de los fondos de cohesión 2014-2020: el caso de Villena (Alicante) / Territorial participatory strategies as instruments of diagnosis and prospective, in the European context of the funds of cohesion 2014-2020 in Villena (Alicante)
185 Francisco José Morales Yago

Evolución de la jerarquía urbana en la Región de Murcia tras más de treinta años de la aprobación del estatuto de autonomía (1982-2014) / Evolution of urban hierarchy in the Region of Murcia thirty years after the adoption of the statute of autonomy (1982-2014)

205 José Luis Rodríguez García

Conservación y gestión del paisaje en el Campo de Albacete / Landscape conservation and management in the Campo de Albacete

227 XANTI SUdUPE Zabalo

El abandono en el paisaje de periferia y periurbano de Bilbao / Abandonment in the periphery and peri-urban landscape of Bilbao

257 M. Antonio Zárate Martín \& InÉs Ortíz Álvarez

Estrategias para la conservación y gestión sostenible de los paisajes culturales urbanos en México y España / Strategies for the conservation and sustainable management of the urban cultural landscapes in México and Spain

\section{MARÍA DEL CARMEN ZORRILLA LASSUS}

La puesta en valor del paisaje a través de la educación, propuesta para el desarrollo de la Isla de Vieques (Puerto Rico) / The enhancement of landscape through education proposal for the development of the island of Vieques (Puerto Rico)

\section{Recensión de un libro · Book Review}

315 Borderías Uribeondo, M.P. \& Muguruza Cañas, M.C.: Impacto ambiental 6101301GRoiAol. (María José Aguilera ArilLa)

\section{Imágenes y palabras · Pictures and words}

323 Francisco josé Morales Yago

Portmán (La Unión-Cartagena): ¿Crónica de un impacto medioambiental en vías de solución? / Portmán (La Unión-Cartagena): chronicle of an environmental impact way of solution?

\section{Comentario de material didáctico · Comment of didactic material}

Mendoza Vargas, Héctor (coord.): Estudios de geografía humana de México. (Alejandro García Ferrero)

Historia de la Geografía Española • History of Geography in Spain 335 Nota preliminar

337 Aurelio Nieto Codina

Paisaje y Geografía en la obra de Eduardo Hernández-Pacheco / Landscape and Geography in the work of Eduardo Hernández-Pacheco 